\title{
Extending Research on a Computer-Based Sight-Word Reading Intervention to a Student with Autism
}

\author{
Jared S. Yaw $\cdot$ Christopher H. Skinner • \\ John Parkhurst • Cora M. Taylor • \\ Joshua Booher • Karen Chambers
}

Published online: 8 January 2011

(C) The Author(s) 2010. This article is published with open access at Springerlink.com

\begin{abstract}
A multiple-baseline design across tasks (i.e., word lists) was used to evaluate the effects of a computer-based sight-word reading intervention (CBSWRI) on the sight-word reading of a sixth-grade student with Autism. Across 3 lists of primer and first-grade Dolch words, the student showed immediate increases in sight-word reading after the CBSWRI was applied. As the student learned 25 words in 16 brief (i.e., $200 \mathrm{~s}$ ) sessions, the efficiency and sustainability of the CBSWRI are discussed along with future research.
\end{abstract}

Keywords Computer-assisted technology - Sight-word reading · Time delay · Autism

Learning to read is a common and serious problem for many students with disabilities (Watson et al. 2009). Individual Education Plans contain more reading

This research was support by the Korn Learning Assessment and Social Skills (KLASS) center at The University of Tennessee.

J. S. Yaw $(\varangle) \cdot$ C. H. Skinner $(\varangle) \cdot J$. Parkhurst $(\varangle) \cdot$ C. M. Taylor $(\bowtie)$

The University of Tennessee, Knoxville, TN, USA

e-mail: jyaw@utk.edu

C. H. Skinner

e-mail: cskinne1@utk.edu

J. Parkhurst

e-mail: jparkhurst197@gmail.com

C. M. Taylor

e-mail: ctaylo63@utk.edu

J. Booher · K. Chambers

Newport City School System, Knoxville, TN, USA 
objectives than any other academic skill objectives (Bos and Vaughn 2008). Although identification and remediation of early literacy skill deficits (e.g., phonemic awareness) may prevent more severe reading problems from developing (Ehri and Nunes 2002; National Institute of Child Health and Human Development 2000), some students continue to struggle with phonetic-based instruction, even when they receive additional support (e.g., response-to-intervention or special education services). In such cases, and particularly when students have intellectual disabilities, some researchers have advocated using whole-word instruction (Browder and Lalli 1991; Burns 2007; Burns and Sterling-Turner 2010). Supplementing early literacy skill instruction with direct whole-word instruction may enhance students' confidence in their reading abilities, improve their daily living skills, and reduce frustration associated with learning to read and/or reading instruction (Bliss et al. 2006; Browder and Lalli 1991; Harris and Sipay 1985).

Many students with autism face challenges when learning to read, including problems with attention, lack of motivation, and deficits related to word decoding and phonemic awareness (Vacca 2007). Though little is known about phonological awareness in children with autism, targeted sight-word interventions have been effective with some children (Gabig 2010). Constant time delay procedures have been effective when applied using flash-card sight-word instruction in students with emotional disorders and intellectual disabilities (Browder et al. 2009; Browder and D'Huyvetters 1988; Cohen et al. 2008; Snell and Gast 1981; Touchette 1971). Constant time delay is a response-prompting procedure that provides students with frequent opportunities to respond, combined with immediate feedback and consequences for correct or incorrect responding (Hughes and Fredrick 2006). During constant time delay, the interval for responding (i.e., time between the presentation of the target stimulus and the prompt that ends the learning trials) is held constant across learning trials (Browder and D'Huyvetters 1988; Touchette 1971).

Researchers who investigated time delay intervals found that students may learn more words when intervals are longer (e.g., 5-s delays as opposed to 2-s delays), perhaps because longer intervals provide students enough time to respond (Rowe 1974; Skinner et al. 1994, 1995; Sterling et al. 1997). However, in many instances, longer response intervals may not enhance learning. Because longer response intervals can reduce learning trial rates, they may impede learning (Skinner et al. 1996, 1997; Skinner 2010). For example, Skinner et al. (2002/1995) re-analyzed the data from the Skinner, Johnson et al. study and showed that when learning rate was precisely measured (using seconds of instructional time as opposed to sessions on the horizontal axis), longer response intervals decreased learning trial rates and learning. A second concern with longer delays is that the reduced pace of responding may enhance off-task behavior (Carnine 1976; Skinner 2002; Windingstad et al. 2009). Therefore, when using constant time delay procedures, the goal may be to provide enough time for students to respond, but not so much time that learning trial rates are significantly reduced (McCallum et al. 2006; Skinner 1998; Skinner et al. 1996).

Recently, researchers used popular software to develop a computer-based sightword reading intervention (CBSWRI) to provide flash card-like sight-word training 
across three students; one receiving remedial reading instruction, one English Language Learning (ELL), and one student with attention-deficit hyperactivity disorder (ADHD; Hilton et al. in press). The CBSWRI involved words being displayed on a computer screen, one word at a time. Students were instructed to try to read the word before they heard a recording of the word. The recording was played $2 \mathrm{~s}$ after the word appeared on the screen (i.e., a constant 2-s time delay). After the recording was played, students repeated the word and a new word was displayed $2 \mathrm{~s}$ later. The recording was designed to end the learning trial, reinforce accurate responding, and provide corrective feedback following errors. By requiring students to repeat the word after they heard the recording, researchers enhanced rates of accurate responding and increased the probability of the last response during each trial being accurate. Each of these procedures has been shown to enhance learning and skill development (Saecker et al. 2009; Skinner and Smith 1992).

There are many advantages in using computer-assisted sight-word instruction. While a student is working with the computer, the teacher can attend to other students or classroom issues (Kodak et al. in press). Although therapists, teachers, and caregivers do not always implement interventions with high levels of integrity (Moore and Fisher 2007; Mueller et al. 2003), computer programs can be used to consistently provide words and prompts (e.g., audio recording of the correct word) as intended (Kodak et al. in press). When comparing personal to computer-assisted instruction, researchers have found higher motivation levels (Heimann et al. 1995; Moore and Calvert 2000) and decreases in behavior problems during the computerassisted instruction (Chen and Bernard-Opitz 1993).

Although results of the initial evaluation study suggested that the CBSWRI improved sight-word reading across two of the three students, internal validity was compromised as one student showed delayed gains (Hilton et al. in press). The current study, initiated by a special education teacher who requested assistance in enhancing sight-word reading in a student with autism, was designed to replicate and extend the CBSWRI research base. Specifically, we attempted to enhance control for threats to internal validity by using a multiple-baseline design across behaviors. Also, we assessed for maintenance and conducted the study with a student with autism.

\section{Methods}

\section{Participants, Materials, and Setting}

The study was conducted in a rural elementary school in the Southeastern United States. Craig, a 12-year-old boy who had been diagnosed with autism, received all his academic instruction in a self-contained special education classroom that included 10 students, one special education teacher and two teacher's aides. The primary experimenter, a Ph.D. student in a school psychology program completing a practicum, applied all procedures in Craig's classroom using one of five computers.

Each word list contained 10 Dolch words. The Dolch Word List is a list of frequently used words compiled by Edward William Dolch, Ph.D. Many of the 220 
Dolch words cannot be "sounded out" using common sound-to-letter implicit phonics patterns and must be learned by sight; hence, the alternative term, "sight word." Teacher judgment was used to select the 30 words targeted in this study. Specifically, Craig's teacher reviewed the Dolch word list and selected the first 30 words that she judged Craig could not read.

Using guidelines provided by Hopkins et al. (in press), the primary researcher used Microsoft ${ }^{\odot}$ PowerPoint $^{\odot}$ to construct the computer-based sight-word reading system (CBSWRS) that included two separate programs, one for assessment and one for intervention. Both programs presented Dolch words in 88 point Arial style font. Words were presented one at a time centered on the screen. The intervention program contained recordings of target words being read, but the assessment program did not include these recording.

Apple $^{\odot}$ GarageBand $^{\circledR}$ software was used to record Craig's responses during assessments. Another graduate student independently scored these recordings which were then used to calculate interobserver agreement.

\section{Design and Dependent Variables}

A multiple-baseline design across tasks (i.e., word lists) was used to evaluate the effectiveness of the CBSWRI on Craig's sight-word reading. Relative to a multiplebaseline design across subjects, this design provides more control for threats to internal validity (e.g., history effects) because the student serves as his own control (Kazdin 2011). The intervention was staggered across three lists (A, B, and C) of 10 Dolch words. The lists were constructed by asking Craig's teacher to review all primer and first-grade Dolch words and select 30 words that Craig could not read. Stratified random assignment (stratified across primer and first-grade levels) was then used to construct three 10 -word lists.

The dependent variable was the number of words read correctly within $2 \mathrm{~s}$. Baseline lasted 3, 9, and 14 sessions for lists A, B, and C, respectively. Decisions on when to apply the CBSWRI to lists were based on visual analysis of time series data (e.g., trend and variability). During baseline and intervention phase assessments, Craig read words from the computer that presented one word at a time for $2 \mathrm{~s}$. Only words read correctly within $2 \mathrm{~s}$ were scored as correct.

\section{Procedures}

\section{General Procedures}

During the first three sessions (i.e., baseline phase for all three word lists), Craig was assessed on each of the three lists of words, each day, for 3 consecutive school days. Following these first three assessment-only sessions, CBSWRI procedures were run each session (2-4 schools days per week depending upon scheduling conflicts). During this intervention phase, the CBSWRI was applied in a staggered fashion to one list at a time. Each session, immediately after the intervention was run, Craig was assessed on all three lists of words using procedures identical to baseline. 
Across all sessions (i.e., baseline and intervention phases), the three lists were assessed in counterbalanced order.

\section{Assessment Procedures}

Craig was placed in front of a computer with the assessment program running and the word START displayed on the screen. The primary experimenter informed Craig that after he clicked START, words would appear on the screen and he should attempt to read them before they disappeared. After Craig started the assessment program, words appeared for $2 \mathrm{~s}$ before they disappeared from the screen. Only words Craig read correctly before they disappeared from the screen were scored as correct. For each assessment, word order was randomized.

An intervention folder was placed on a classroom computer. This folder contained five versions of the CBSWRI (one for each day of the week) for each list. Each CBSWRI included 40 learning trials as the target list of 10 words was repeated four times. The CBSWRI was initiated when Craig clicked START. Once started, sight-words appeared on the screen for $2 \mathrm{~s}$, followed by the primary experimenter's voice recording of the sight-word, and another 2-s delay before the next word appeared. Craig was instructed to try and read the word before the recording sounded (i.e., "try to beat the tape") and repeat the word after the recording. The CBSWRI required about $200 \mathrm{~s}$.

\section{Maintenance}

After the intervention was switched from word list A to word list B and again from word list B to word list C, we continued to assess all three sets of words, each session, immediately after the intervention was applied. These procedures allowed us to hold assessment conditions constant across phases. Also, these data provided us with measures of maintenance across word lists A and B.

\section{Interobserver Agreement}

Each assessment session was audio-taped using Apple ${ }^{\odot}$ GarageBand $^{\odot}$ software. Another school psychology student independently listened to $60 \%$ of the assessment sessions and recorded words read correctly/incorrectly within $2 \mathrm{~s}$. For each session, percent interobserver agreement was calculated by dividing the number of agreements on words read correctly within $2 \mathrm{~s}$ by the number of agreements plus disagreements and multiplying by $100 \%$. For each session, interobserver agreement was $100 \%$.

\section{Results}

Figure 1 displays the number of words Craig read correctly within $2 \mathrm{~s}$ across word lists and phases. Across lists, Craig read 0 or 1 word(s) correctly within 2 s during baseline. Baseline phase data show no evidence of increasing trends. Across all 


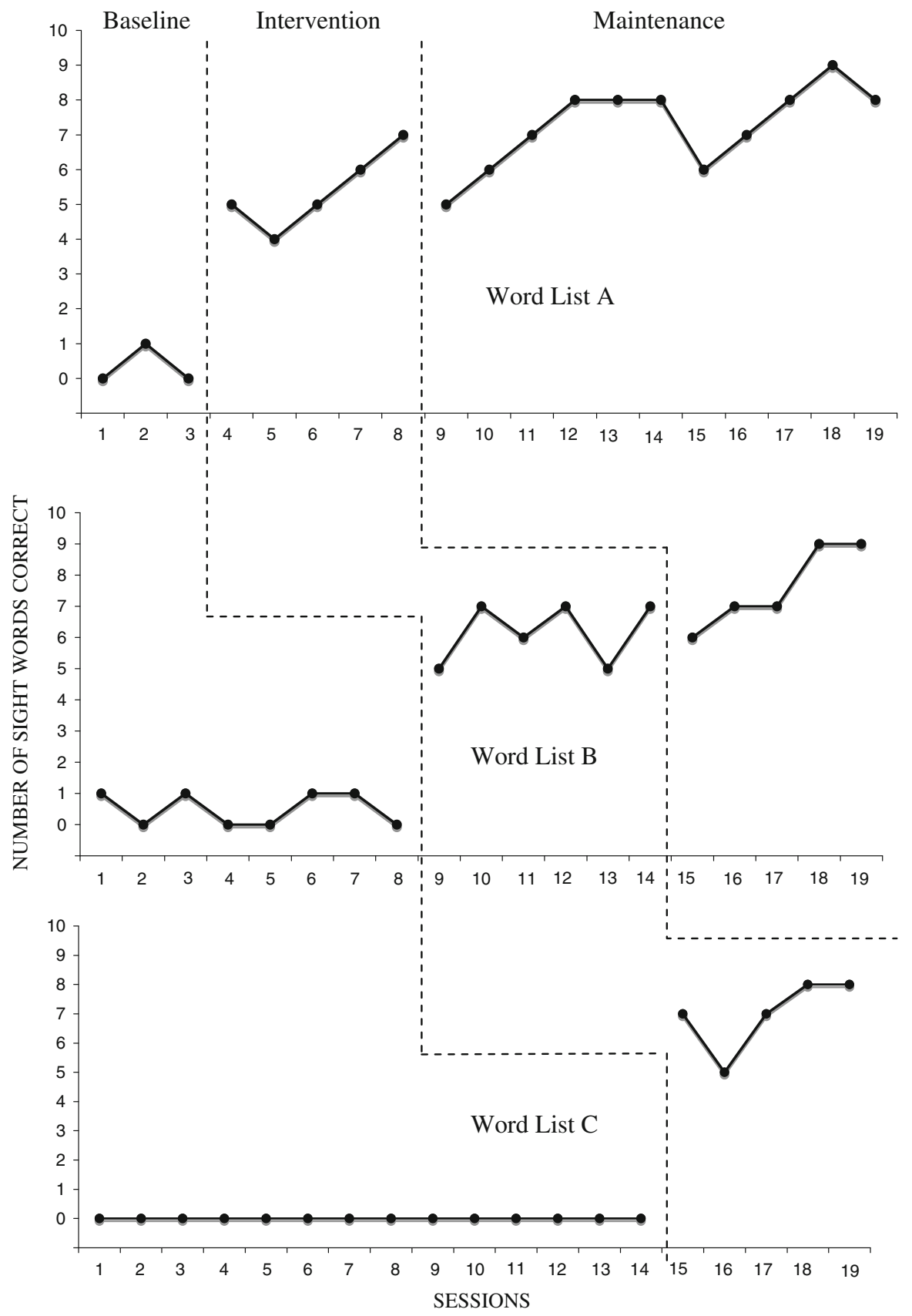

Fig. 1 Words Craig read correctly within $2 \mathrm{~s}$ across lists and phases 
three lists, immediately after the CBSWRI was applied, Craig increased his words read correctly within $2 \mathrm{~s}$ to at least 4 with no concomitant increases on untargeted lists. For each list, there were no overlapping data across phases. Across all baseline assessments, Craig read only 2 words correctly within 2 s. On the last assessment, Craig read 25/30 words correctly within 2 s. Data collected after the CBSWRI were removed from lists A and B show that Craig maintained and even slightly enhanced his automatic reading after the CBSWRI was withdrawn and applied to subsequent word list(s).

\section{Discussion}

Previous researchers found evidence that the CBSWRI enhanced Dolch word reading in three students; one ELL student, one with ADHD, and one receiving remedial reading instruction (Hilton et al. in press). We enhanced and extended this research in several ways. Relative to Hilton et al.'s findings, the current baseline data were more stable and the changes in automatic sight-word reading were more immediate across all three series (word lists in the current study, students in Hilton et al.). Additionally, the current finding provided three replications of treatment effects within the same subject. Thus, the current results provide stronger evidence of a treatment effect (Kazdin 2011). Also, this was the first study to show that the CBSWRI could be used to enhance sight-word reading in a student with autism. Finally, the current study advanced previous research by showing that words learned during CBSWRI were maintained after the intervention was withdrawn and applied to a new set of words. These maintenance data are critical as enhancing sight-word reading is only functional if students maintain their ability to read targeted words (Burns and Sterling-Turner 2010).

Some have suggested that enhancing students' ability to automatically read commonly used words may improve students' comprehension and confidence in their reading abilities, while reducing frustration associated with learning to read and/or reading instruction (Bliss et al. 2006; Browder and Lalli 1991; Catts et al. 2006; Harris and Sipay 1985; Nist and Joseph 2008). Others have suggested that repetitive sight-word reading activities such as the CBSWRI may hinder the development of reading skills in students with autism because they may result in students being excluded from rich and meaningful literacy experiences like storytelling, journal-keeping, reading, and writing (Kluth and Darmody-Latham 2003). Perhaps both points are correct; sight-word training is effective, but should not take so much instructional time that it detracts from other literacy activities (Skinner 2008).

The CBSWRI used in the current study took approximately $200 \mathrm{~s}$ over 16 days (total time on CBSWRI $=3,200 \mathrm{~s}$ or about $53.5 \mathrm{~min}$ ). As Craig appeared to learn to read about 25 words automatically and evidence suggests that he maintained these gains, his learning rate was over about .47 words learned for every min of instruction. When one considers how many min were devoted to other forms of literacy instruction over the course of this sixth-grade student's education, these results appear impressive. Also, Craig's teacher indicated that this brief instruction 
took little time and did not interfere with other literacy activities. Thus, the current study demonstrates that it is possible to effectively and efficiently improve sightreading automaticity in a student with autism using the CBSWRI.

In an attempt to enhance learning trial rates and maintain on-task behaviors, researchers and educators selected a 2 -s constant time delay. Researchers may want to consider conducting additional treatment comparison studies to determine whether learning rates vary as a function of time delays (see Skinner et al. 1995/ 2002). Additionally, researchers should consider conducting studies comparing constant time delay procedures with varying time delay procedures. For example, in order to reduce the likelihood of inaccurate responding, researchers may want to start with no or very brief delays, increase these delays to allow for independent responding, and finally decrease them to encourage rapid or automatic responding (see McCallum et al. 2006; Windingstad et al. 2009).

Although the intervention used in the current study appears simple, there are several components that may or may not have influenced sight-word learning. The student was trained to attempt to read the word within $2 \mathrm{~s}$ and then use the recording as feedback. Future researchers may want to conduct component analysis studies to determine whether this feedback served to reinforce accurate responding and/or punish inaccurate responding (Skinner and Smith 1992). Also, future researchers should examine whether having the student repeat the word after hearing it on the tape improves learning by enhancing rates of accurate responding and/or increasing the probability that the last response was accurate (Saecker et al. 2009).

The current results support the efficacy of the CBSWRI; however, there are limitations with this study that should be addressed before strong recommendations and conclusions can be drawn. The current study was conducted with only one student. To better evaluate these procedures, additional studies are needed with more students with autism and across populations (e.g., students with intellectual disabilities, students with EBD). Because one purpose of this research was to provide a graduate student with experience in intervention development, application, and evaluation, the graduate student conducted or supervised all intervention and assessment procedures. Therefore, Craig never administered the intervention without support from the graduate student. Educators may be more likely to employ the CBSWRI if future researchers can show that similar results can be obtained when students self-administer the intervention.

Developing early literacy skills is thought to enhance word recognition (Liberman et al. 1974; Vellutino and Scanlon 1987). Future researchers may want to examine another possibility by determining whether enhancing sight-word reading enhances both early (e.g., phonemic awareness) and advanced (e.g., comprehension) literacy skills in students with disabilities. Additionally, researchers should attempt to determine whether this procedure enhances a students' ability to read and understand words printed on paper (as opposed to on a computer screen) and in context (e.g., within sentences or on a public sign). Although our postintervention assessments for word lists A and B suggest gains were maintained, because these assessments were conducted each session, the assessments themselves may have contributed to maintenance (Skinner and Shapiro 1989). To better evaluate maintenance, future researchers should assess maintenance over longer 
intervals of time when no treatment or assessments of learned words were conducted.

Kluth and Darmody-Latham (2003) characterized repetitive drill-and-practice activities as monotonous. However, Craig appeared to enjoy the CBSWRI and learning to read words accurately and rapidly. Therefore, future research should test this assumption that the CBSWRI and other effective but repetitive drill-andpractice procedures are unacceptable to students.

Vacca (2007) indicated that many students with autism have difficulty learning to read and that these difficulties are related to attention and motivation deficits. The CBSWRI used in the current study was designed to address these concerns by using computers (enhance motivation, see Heimann et al. 1995; Moore and Calvert 2000) to occasion high rates of responding (enhance attention and on-task levels, see Carnine 1976; Hawkins et al. 2005; McCurdy et al. 2001; Windingstad et al. 2009) and provide prompts that served as feedback (enhance learning when accurate responding occurs at high rates (see Skinner and Smith 1992; Saecker et al. 2009). As the current findings suggest that this CBSWRI was effective, acceptable, efficient, and sustainable, researchers and educators should continue to develop and evaluate other computer-based procedures that occasion high rate of active, accurate, academic responding.

Open Access This article is distributed under the terms of the Creative Commons Attribution Noncommercial License which permits any noncommercial use, distribution, and reproduction in any medium, provided the original author(s) and source are credited.

\section{References}

Bliss, S., Skinner, C. H., \& Adams, R. (2006). Enhancing an English language learning fifth-grade student's sight-word reading with a time-delay taped-words intervention. School Psychology Review, 35, 663-670.

Bos, C. S., \& Vaughn, S. (2008). Strategies for teaching students with learning and behavioral problems (7th ed.). Boston: Allyn \& Bacon.

Browder, D. M., Ahlgrim-Delzell, L., Spooner, F., Mims, P. J., \& Baker, J. N. (2009). Using time delay to teach literacy to students with severe developmental disabilities. Exceptional Children, 75, 343-364.

Browder, D. M., \& D'Huyvetters, K. K. (1988). An evaluation of transfer of stimulus control and of comprehension in sight word reading for children with mental retardation and emotional disturbance. School Psychology Review, 17, 331-342.

Browder, D. M., \& Lalli, J. S. (1991). Review of research on sight word instruction. Research in Developmental Disabilities, 12, 203-228.

Burns, M. K. (2007). Comparison of drill ratio and opportunities to respond when rehearsing sight words with a child with mental retardation. School Psychology Quarterly, 22, 250-263.

Burns, M. K., \& Sterling-Turner, H. E. (2010). Comparison of efficiency measures for academic interventions based on acquisition and maintenance. Psychology in the Schools, 47, 126-134.

Carnine, D. W. (1976). Effects of two teacher presentation rates on off-task behavior, answering correctly, and participation. Journal of Applied Behavior Analysis, 9, 199-206.

Catts, H. W., Adolf, S. M., \& Weismer, E. S. (2006). Language deficits in poor comprehenders: A case for the simple view of reading. Journal of Speech, Language, Hearing Research, 49, 278-293.

Chen, S. H. A., \& Bernard-Opitz, V. (1993). Comparison of personal and computer-assisted instruction for children with autism. Mental Retardation, 31, 368-376.

Cohen, E. T., Heller, K. W., Alberto, P., \& Fredrick, L. D. (2008). Using a three-step decoding strategy with constant time delay to teach word reading to students with mild and moderate mental retardation. Focus on Autism and Other Developmental Disabilities, 23, 67-78. 
Ehri, L. C., \& Nunes, S. R. (2002). The role of phonemic awareness in learning to read. In A. E. Farstrup \& S. J. Samuels (Eds.), What research has to say about reading instruction (pp. 110-139). Newark, DE: International Reading Association.

Gabig, C. S. (2010). Phonological awareness and word recognition in reading by children with autism. Communication Disorders Quarterly, 31(2), 67-85.

Gray, C. A. (1998). Social stories and comic strip conversations with students with Asperger syndrome and high-functioning autism. In E. Schopler, G. B. Mesibov, \& L. J. Kunce (Eds.), Asperger syndrome or high-functioning autism? (pp. 167-198). New York: Plenum Press.

Harris, A. J., \& Sipay, E. R. (1985). How to increase reading ability: A guide to developmental and remedial methods (8th ed.). New York: Longman.

Hawkins, J., Skinner, C. H., \& Oliver, R. (2005). The effects of task demands and additive interspersal ratios on fifth-grade students' mathematics accuracy. School Psychology Review, 34, 543-555.

Heimann, M., Nelson, K. E., Tjus, T., \& Gillberg, C. (1995). Increasing reading and communication skills in children with autism through an interactive multimedia computer program. Journal of Autism and Developmental Disorders, 25(5), 459-480.

Hilton, A. N., Hopkins, M. B., Skinner, C. H., \& McCane-Bowling (in press). Enhancing sight-word reading in second-grade students using a computer-based sight-word reading system. Journal of Evidence-Based Practices in the Schools.

Hopkins, M. B., Hilton, A. N., \& Skinner, C. H. (in press). Implementation guidelines: How to design a computer-based sight-word reading system using Microsoft ${ }^{\circledR}$ PowerPoint $^{\circledR}$. Journal of EvidenceBased Practices in the Schools.

Hughes, T. A., \& Fredrick, L. D. (2006). Teaching vocabulary with students with learning disabilities using classwide peer tutoring and constant time delay. Journal of Behavioral Education, 15, 1-23.

Kazdin, A. E. (2011). Single-case research designs: Methods for clinical and applied settings (2nd ed.). New York: Oxford University Press.

Kliewer, C. (1998). Citizenship in the literate community: Ethnography of children with Down Syndrome and the written word. Exceptional Children, 64, 167-180.

Kluth, P., \& Darmody-Latham, J. (2003). Beyond sight words: Literacy opportunities for students with autism. The Reading Teacher, 56, 532-535.

Kodak, T., Fisher, W. W., Clements, A., \& Bouxsein, K. J. (in press). Effects of computer-assisted instruction on correct responding and procedural integrity during early intensive behavioral intervention. Research in Autism Spectrum Disorders.

Liberman, I. Y., Shankweiler, D., Fischer, F. W., \& Carter, B. (1974). Explicit syllable and phoneme segmentation in the young child. Journal of Experimental Child Psychology, 18, 201-212.

McCallum, E., Skinner, C. H., Turner, H., \& Saecker, L. (2006). The taped-problems intervention: Increasing multiplication fact fluency using a low-tech, class-wide, time- delay intervention. School Psychology Review, 35, 419-434.

McCurdy, M., Skinner, C. H., Grantham, K., Watson, T. S., \& Hindman, P. M. (2001). Increasing on-task behavior in an elementary student during mathematics seat-work by interspersing additional brief problems. School Psychology Review, 30, 23-32.

Moore, M., \& Calvert, S. (2000). Brief report: Vocabulary acquisition for children with autism: Teacher or computer instruction. Journal of Autism and Developmental Disorders, 30, 359-362.

Moore, J. W., \& Fisher, W. W. (2007). The effects of videotape modeling on staff acquisition of functional analysis methodology. Journal of Applied Behavior Analysis, 40, 197-202.

Mueller, M. M., Piazza, C. C., Moore, J. W., Kelley, M. E., Bethke, S. A., Pruett, A. E., et al. (2003). Training parents to implement pediatric feeding protocols. Journal of Applied Behavior Analysis, $36,545-562$.

National Institute of Child Health and Human Development. (2000). Report of the national reading panel: Teaching children to read (NIH Publication No. 00-4769). Washington, D.C.: Government Printing Office.

Nist, L., \& Joseph, L. M. (2008). Effectiveness and efficiency of flashcard drill instructional methods on urban first-graders' word recognition, acquisition, maintenance, and generalization. School Psychology Review, 37, 294-308.

Rowe, M. (1974). Wait-time and rewards as instructional variables, their influence on language, logic, and fate control: Part one-wait time. Journal of Research in Science Teaching, 17, 469-475.

Saecker, L., Skinner, C. H., Brown, K. S., \& Roberts, A. (2009). Cover, copy, and compare to enhance number-writing accuracy: Linking responsiveness data to intervention modifications. Journal of Evidence Based Practices in the Schools, 10, 171-187. 
Skinner, C. H. (1998). Preventing academic skills deficits. In T. S. Watson \& F. Gresham (Eds.), Handbook of child behavior therapy: Ecological considerations in assessment, treatment, and evaluation (pp. 61-83). New York: Plenum.

Skinner, C. H. (2002). An empirical analysis of interspersal research: Evidence, implications and applications of the discrete task completion hypothesis. Journal of School Psychology, 40, 347-368.

Skinner, C. H. (2008). Theoretical and applied implications of precisely measuring learning rates. School Psychology Review, 37, 309-315.

Skinner, C. H. (2010). Applied comparative effectiveness researchers must measure learning rates: A commentary on efficiency articles. Psychology in the Schools, 47, 166-172.

Skinner, C. H., Belfiore, P. J., Mace, H. W., Williams, S., \& Johns, G. A. (1997). Altering response topography to increase response efficiency and learning rates. School Psychology Quarterly, 12, 54-64.

Skinner, C. H., Belfiore, P. B., \& Watson, T. S. (1995/2002). Assessing the relative effects of interventions in students with mild disabilities: Assessing instructional time. Journal of Psychoeducational Assessment, 20, 345-356. (Reprinted from Assessment in Rehabilitation and Exceptionality, 2, 207-220, 1995).

Skinner, C. H., Fletcher, P. A., \& Henington, C. (1996). Increasing learning trial rates by increasing student response rates. School Psychology Quarterly, 11, 313-325.

Skinner, C. H., Johnson, C. W., Larkin, M. J., Lessley, D. J., \& Glowacki, M. L. (1995b). The influence of rate of presentation during taped-words interventions on reading performance. Journal of Emotional and Behavioral Disorders, 3, 214-223.

Skinner, C. H., \& Shapiro, E. S. (1989). A comparison of a taped-words and drill interventions on reading fluency in adolescents with behavior disorders. Education and Treatment of Children, 12, 123-133.

Skinner, C. H., \& Smith, E. S. (1992). Issues surrounding the use of self-managed interventions for increasing academic performance. School Psychology Review, 21, 202-210.

Skinner, C. H., Smith, E. S., \& McLean, J. E. (1994). The effects of intertrial interval duration on sightword learning during constant time delay. Behavioral Disorders, 19, 98-107.

Snell, M. E., \& Gast, D. L. (1981). Applying time delay procedure to the instruction of the severely handicapped. The Journal of the Association for the Severely Handicapped, 6, 3-14.

Sterling, H. E., Robinson, S. L., \& Skinner, C. H. (1997). The effects of two taped-words interventions on sight-word reading in students with mental retardation. Journal of Behavior Education, 7, 25-32.

Touchette, P. E. (1971). Transfer of stimulus control: Measuring the moment of transfer. Journal of the Experimental Analysis of Behavior, 15, 347-354.

Vacca, J. S. (2007). Autistic children can be taught to read. International Journal of Special Education, 22, 54-61.

Vellutino, F. R., \& Scanlon, D. M. (1987). Phonological coding, phonological awareness, and reading ability: Evidence from a longitudinal and experimental study. Merrill-Palmer Quarterly, 33, 321-363.

Watson, M., Fore, C., I. I. I., \& Boon, R. T. (2009). Corrective feedback of oral decoding errors for diverse learners with reading disabilities: The effects of two methods on reading fluency. International Journal of Special Education, 24(1), 20-31.

Windingstad, S., Skinner, C. H., Rowland, E., Cardin, E., \& Fearrington, J. (2009). Extending research on a class-wide, math fluency building intervention: Applying taped-problems in a second-grade classroom. Journal of Applied School Psychology, 25, 364-381. 